*Note: This is an uncorrected version of an author's manuscript accepted for publication.*Copyediting, typesetting, and review of the resulting proofs will be undertaken on this manuscript before final publication. During production and prepress, errors may be discovered that could affect the content.

\title{
Cortisol response to stress: The role of expectancy and anticipatory stress regulation.
}

\author{
Matias M. Pulopulos*a, Chris Baeken ${ }^{\mathrm{bcd}}$ and Rudi De Raedt ${ }^{\mathrm{a}}$
}

aDepartment of Experimental Clinical and Health Psychology, Ghent University, Ghent, Belgium

${ }^{b}$ Department of Psychiatry and Medical Psychology, Ghent University, Ghent, Belgium

'Ghent Experimental Psychiatry (GHEP) Lab, Ghent, Belgium

${ }^{d}$ Department of Psychiatry, University Hospital (UZBrussel), Brussels, Belgium

\footnotetext{
* Corresponding author: Matias M. Pulopulos, Ph.D. Department of Experimental Clinical and Health Psychology, Ghent University, Henri Dunantlaan 2 - 9000 Ghent, Belgium. Tel: +32 (0)9 2646472.

Email: matias.pulopulos@ugent.be.
} 


\section{Abstract}

An exacerbated physiological response to stress is associated with the development of stress-related disorders (e.g., depression and anxiety disorders). Recently, it has been proposed that individuals with high expectancies of being able to deal with stressful situations will activate regulatory mechanisms during the anticipation of the stressful event that would improve stress regulation. To test this hypothesis, 52 women in young adulthood ( $M=21.06$; $S D=2.58)$ anticipated and performed a laboratory-based stress task after receiving positive or negative feedback on their abilities to deal with stressful events. Heart rate variability and salivary cortisol were assessed throughout the experimental protocol. Participants receiving positive feedback (i.e., High Expectancy group) showed a more positive anticipatory cognitive stress appraisal (i.e., they anticipated the stress task as less threatening/challenging, and they perceived that they were more able to deal with it), and they showed a lower cortisol response to stress. Moreover, a more positive anticipatory cognitive stress appraisal was associated with better anticipatory stress regulation (indexed as less decrease in heart rate variability), leading to a lower cortisol response. Our results indicate that people with positive expectancy initiate mechanisms of anticipatory stress regulation that enhance the regulation of the physiological stress response. Expectancy and anticipatory stress regulation may be key mechanisms in the development and treatment of stress-related disorders.

Keywords: cortisol; stress; expectancy; HRV; anticipation; TSST. 


\section{Introduction}

Inability to handle everyday stress leads to exacerbated physiological responses and is associated with the development and course of adverse long-term health outcomes, including a wide range of psychological disorders such as major depression, substance abuse, and anxiety disorders (Duffing et al., 2014; McEwen, 2008; Sinha, 2001). Under stressful conditions, the hypothalamuspituitary-adrenal (HPA) axis is activated, resulting in an increase in cortisol secretion that peaks between 20 and 40 min after initiation of the stressful event (Dickerson et al., 2004). There are large inter-individual differences in the cortisol response to stress, and it has been proposed that cortisol and the activity of the HPA axis play a central role in the onset and maintenance of stress-related psychological illnesses such as depression and anxiety disorders (Faravelli et al., 2012; Herbert, 2013; Morris et al., 2012). High levels of cortisol have been associated with a decreased dorsolateral prefrontal cortex (DLPFC) activity, and a prolonged activation of the amygdala, a deregulation which may lead to reduced abilities to regulate emotion, sustained negative mood and may (hyper)activate the HPA axis during the confrontation with future stressful events (De Raedt and Koster, 2010). Along with this line, individuals showing higher cortisol reactivity to stress are at greater risk for experiencing subsequent depressive symptoms (Morris et al., 2012), and insecure attachment styles -a risk factor for developing social anxiety disorder- have been associated with larger cortisol responses to stress (Manning et al., 2017; Smyth et al., 2015). Given the relationship between the activity of the HPA axis under stressful conditions and the development of psychological disorders such as depression and anxiety, it is crucial to understand which interindividual factors in stress regulation may explain the differences in the cortisol response to stress.

The period of anticipation of stressful events may be critical to understanding the process of stress regulation (e.g., Ottaviani, 2018; Salvador and Costa, 2009). Indeed, it has been proposed that, when a stressful situation is anticipated, individuals make behavioral, cognitive, and physiological adjustments that facilitate the process of coping with the upcoming stressor (Pulopulos et al., 2018a; Schulkin, 2011; Schulkin et al., 1994; Turan et al., 2015). As such, previous research has highlighted 
the relevance of stress anticipation in the development of stress-related disorders (Brosschot et al., 2006; Brosschot et al., 2017). However, it is still not well understood how psychological and physiological processes that occur during stress anticipation affect the regulation of the cortisol response to stress. Within this context, De Raedt and Hooley (2016) have proposed the Neurocognitive framework for Regulation Expectation (NFRE), a framework in which stress anticipation plays a central role in the process of stress regulation and the development of depression and other stress-related psychopathologies. The NFRE proposes that, when a stressful event is anticipated, individuals with high expectancies of being able to deal with the future situation successfully will engage in a proactive stress anticipation (i.e., anticipatory stress regulation). Importantly, this anticipatory stress regulation would facilitate the process of regulation of the stress response during the actual confrontation with the stressor. De Raedt and Hooley (2016) suggest that a proactive anticipation of the stressful situation (e.g., using effective strategies of emotion regulation during stress anticipation) will be associated with a sustained anticipatory activity of the DLPFC. As proposed by several authors, an increase in DLPFC activity may reduce the HPA axis response to stress through indirect and inhibitory connections with the amygdala (Baeken et al., 2010, 2014; Herman et al., 2005).

Previous research also provided support for the idea that expectancy may play a role in the regulation of the cortisol response to stress (Gaab et al., 2003; Gaab et al., 2005; Ursin and Eriksen, 2010). In a recent study in healthy participants, Salzmann et al. (2018) investigated the effect of brief psychological interventions that aimed at fostering gratitude, distraction, or personal control expectations on the physiological response to a physical and psychological stress task (i.e., Maastricht Acute Stress Test; Smeets et al., 2012). The participants were asked to write about the possibilities and strategies involved in how they dealt successfully with previous stressors to optimize personal control expectations, to write a gratitude-letter or to perform a distraction writing task. They observed that optimizing expectations and distraction before stress reduced the cortisol response to stress when compared with the intervention fostering gratitude. Moreover, closely related with the concept of expectancy, primary appraisal (i.e., the evaluation of the upcoming event as a threatening 
or challenging situation with potential to disrupt well-being) and secondary appraisal (i.e., the perception of the own ability to cope with the threatening or challenging situation) are critical determinants of the process of stress regulation (Lazarus and Folkman, 1987). As proposed by Lazarus (2001), primary and secondary appraisal are interdependent, they have a mutual influence (e.g., a low secondary appraisal can only be interpreted if scores in primary appraisal are taken into account), and they are parts of a common process known as anticipatory cognitive stress appraisal. A negative anticipatory cognitive stress appraisal indicates that the individual anticipates that the upcoming situation has the potential to disrupt well-being or homeostasis, and they perceive that they do not have enough resources to deal with this situation. Previous studies have shown that a more negative anticipatory cognitive stress appraisal is associated with higher cortisol response to stress (Gaab et al., 2005; Juster et al., 2012; although this result has not always been observed Zandara et al., 2016). A crucial question remains whether positive and negative expectancy provokes a different stressinduced cortisol response. Moreover, it is still not known how expectancy may shape the cortisol response to stress.

Following the NFRE, higher positive expectancy will be associated with a proactive anticipation of stress, which will be reflected in an improved anticipatory stress regulation, resulting in a dampened response to stress. In line with this idea, Nasso et al. (2018) have recently shown that, when anticipating a stressful task (i.e., giving a speech while being recorded), individuals using cognitive reappraisal (i.e., an adaptive cognitive emotion regulation strategy) showed better anticipatory stress regulation than individuals using catastrophizing (i.e., a maladaptive cognitive emotion regulation strategy). Moreover, we have recently demonstrated that better anticipatory stress regulation prior a stressful situation (i.e., giving a speech and arithmetic task while being recorded) was associated with lower stress-induced cortisol response (Pulopulos et al., 2018a). Importantly, as a marker of anticipatory stress regulation, these two studies measured the change from baseline to anticipation in the vagally mediated heart rate variability (HRV). High HRV is considered a marker of emotion regulation and stress adaptability, and it has been associated with increased PFC activity (Makovac et 
al., 2017; Park et al., 2014; Thayer et al., 2012; Vanderhasselt et al., 2015). These results suggest that higher HRV during anticipation would be observed in individuals who successfully initiate mechanisms to regulate stress and to prepare themselves for the upcoming stressor, leading to an increase in PFC activity and facilitating the actual confrontation with the stressful event (Pulopulos et al., 2018a). Following these observations, one could expect that when a stressful situation is anticipated, a positive expectancy will be associated with less decreases in HRV (i.e., better anticipatory stress regulation), leading to lower cortisol response to stress. However, this mechanism has never been investigated; and research using an experimental manipulation is needed to establish such a causal pathway.

In the current study, we aimed at investigating whether manipulation of expectancy (High vs. Low expectancy) affects the cortisol response to stress. A group of healthy young women completed an online questionnaire about their ability to deal with stressful situations. Before coming to the lab and independently of their response to the questionnaire, the participants were randomly assigned to two groups (i.e., High Expectancy or Low Expectancy). Participants in the High Expectancy group were informed that, based on the responses to the questionnaire, they have good abilities to deal with socially stressful situations. Participants in the Low expectancy received negative feedback on their abilities to deal with socially stressful situations. After receiving the feedback, they performed a laboratory-based social stress task. Mood, cortisol levels and HRV were measured throughout the session. We hypothesized that the High Expectancy group (i.e., individuals receiving positive feedback on their abilities to deal with socially stressful situations) would show better anticipatory stress regulation (assessed using HRV measures), and lower cortisol response to stress compared to the Low Expectancy group. Moreover, in a mediation model, we tested whether a negative anticipatory cognitive stress appraisal would be associated with worse anticipatory stress regulation (assessed as the decrease in HRV from baseline to anticipation), leading to lower cortisol response to the stressor.

\section{Methods.}

\subsection{Participants.}


Healthy female undergraduates from Ghent University between 18 and 30 years old were recruited for this study. Participants were selected according to the following criteria: no use of medication that may affect cortisol levels, cognitive and cardiovascular activity; no current (or history of) neurological or psychiatric illness; and smoking less than ten cigarettes per day. In order to control for the effects of sex and menstrual cycle on the cortisol response to stress (for a review see Pulopulos et al., 2018b), only women taking hormonal contraceptives were included in this study. Sixty-seven adult healthy females participated in this study (High Expectancy group=34, Low Expectancy group=33). However, some participants were excluded from the final study sample, and we report here the results of the analyses with 25 participants in the High Expectancy group ( $\mathrm{M}$ age = $20.52, S D=2.10)$ and 27 participants in the Low Expectancy group ( $M$ age $=21.00, S D=2.43)$. In supplementary material, we report the results of the analyses with 29 participants in the High Expectancy group $(\mathrm{M}$ age $=20.67, \mathrm{SD}=2.25)$ and 30 participants in the Low Expectancy group $(\mathrm{M}$ age $=21.17$, $\mathrm{SD}=2.61)$ (see Data Management and Statistical Analyses section for a description of the exclusion of participants from the analyses).

\subsection{Questionnaires.}

\section{Baseline measures.}

To check for differences in trait and state factors that may affect the physiological response to stress, we assessed depressive symptoms using the Beck Depression Inventory-II (Beck et al., 1996; Dutch translation by Van der Does, 2002), brooding and reflective rumination using the Ruminative Responses Scale (Nolen-Hoeksema and Morrow, 1991; Dutch translation by Raes et al., 2003), selfesteem using the Rosenberg Self-Esteem Scale (Rosenberg, 1965; Dutch translation by Franck et al., 2008), perceived stress in the previous month using the Perceived Stress Scale (Cohen et al., 1983) and general self-efficacy using the Generalized Self-Efficacy Scale (Schwarzer and Jerusalem, 1995; Dutch translation by Teeuw et al., 1994).

\section{Cognitive stress appraisal.}


To investigate whether the manipulation affected expectancy, the Dutch translation of the Primary Appraisal Secondary Appraisal (PASA; Gaab et al., 2005) ${ }^{1}$ scale was used to assess the cognitive appraisal during the anticipation of the stress task. Based on the transactional stress theory (Lazarus and Folkman, 1987), the PASA scale is composed of two situation-specific subscales assessing "Primary appraisal" (i.e., how threatful and challenging the situation is perceived), and "Secondary appraisal" (i.e., Self-concept of own competence and control expectancy). The scale has 16 items, rated on a 6-point Likert scale (ranging from $1=$ Totally disagree, to $6=$ Totally agree). Importantly, the PASA allows the calculation of a global measure of anticipatory cognitive stress appraisal, a stress index which sets the two appraisals in relation to each other. The anticipatory cognitive stress appraisal was calculated as the difference between secondary and primary appraisal (secondary appraisal minus primary appraisal) $)^{2}$. Higher scores reflect a more positive anticipatory cognitive stress appraisal.

\subsection{Psychological stress response}

Nine Visual Analogue Scales (VAS; McCormack et al., 1988) were used to assess changes in anxiety, stress perception, anger, worry, motivation, fatigue, cheerfulness, tension, and depression. Each horizontal line was ten centimeters long, and participants had to indicate their perception of their affective state. The anchors were "not at all" and "as stressed as I can imagine." The VASs were recorded using the software Tscope5 (Stevens et al., 2006). Due to technical issues, some items for different participants could not be recorded. Therefore, 42 participants were included in the analyses with VASs data (High Expectancy=23, Low Expectancy=20).

\subsection{Physiological stress response}

To measure cortisol levels, participants provided saliva samples by using salivettes (Sarstedt, Nümbrecht, Germany). They were instructed to keep the cotton swab in their mouths for exactly 2

\footnotetext{
1 The scale was translated into Dutch and back translated into English. The final English version was approved by the author of the scale.

${ }^{2}$ In the original scale, the anticipatory cognitive stress appraisal is calculated as Primary appraisal minus Secondary appraisal. In this study, the anticipatory cognitive stress appraisal index was reversed to make easier the interpretation of the results.
} 
min and move the swab around in a circular pattern to collect saliva from all salivary glands. The salivettes were stored at $-20 \stackrel{\circ}{ } \mathrm{C}$ until the samples were analyzed at Dresden Lab-Service GmbH (Germany) using a commercially available enzyme-linked immunosorbent assay (IBL International, Hamburg, Germany) with an expected lower and upper detection limits of $0.41 \mathrm{nmol} / \mathrm{L}$ and $110.4 \mathrm{nmol} / \mathrm{L}$, and an inter and intra-assay coefficient interval lower than $5 \%$.

To assess changes in HRV, heart rate data was continuously recorded throughout all the sessions using a telemetric heart rate monitor (Polar v800) with a Polar $\mathrm{H} 10$ heart rate sensor and a pro chest strap placed just below the participant's chest muscles. Resulting R-to-R intervals were imported to Kubios 3.0.2 (Tarvainen et al., 2002; Tarvainen et al., 2014), a software specifically designed for advanced HRV analysis. Artifacts were corrected, and the R-to-R intervals interpolated using automatic algorithms from Kubios. The data from one participant during the recovery phase had to be excluded because the signal was too noisy. As an index of HRV, we used the widely utilized root mean square successive difference (RMSSD). The RMSSD is an index of vagal tone that is relatively free of respiratory influences, and that is considered an index of successful emotion and stress regulation (Fagundes et al., 2011; Laborde et al., 2017; Nasso et al., 2018; Sghir et al., 2012; Thayer et al., 2012). The percentage of successive normal sinus RR intervals more than 50ms (pNN50) is also an index of HRV that reflects vagal activity (Laborde et al., 2017). The conclusions of the study are the same if pNN50 is used in the analyses.

\subsection{Stress task}

A modified version of Trier Social Stress Test (TSST; Kirschbaum et al., 1993) was used to produce stress in the participants. This laboratory-based stress task includes three different phases: (I) Introduction to the task. A phase in which the participants are informed about the task that they must perform. (II) Anticipatory phase. After the introduction phase, participants have time to prepare themselves to perform the task. (III) Free Speech and Arithmetic task. During this phase, participants have to perform a free speech (i.e., a job interview) and an arithmetic task ( $5 \mathrm{~min}$ each) in front of a panel while their performance is being recorded. During the job interview, the participants' main 
goal was to convince the evaluators that they were the best candidate for a job that they desired. Because we are especially interested in stress anticipation, following Engert et al. (2013) the anticipatory phase lasted $15 \mathrm{~min}$. In this study, the participants performed the free speech and arithmetic task in a room in front of a window with a one-way mirror, and they were told that two persons were behind the mirror and that they will evaluate their performance. The experimenter was also in the room and provided feedback to the participant. For instance, the experimenter was the person who informed the participants that they still have more time to talk if they stopped talking before the end of the 5 minutes during the free speech and provided feedback about their mistakes during the arithmetic task.

\subsection{Procedure}

The participants provided written informed consent, and the study was approved by the faculty ethical committee at Ghent University. The study had two separated parts: an online questionnaire and a laboratory session.

Online questionnaire: First, participants were asked to fill in an online questionnaire at least two days before the laboratory session. This questionnaire consisted of 35 items that included the Generalized Self-Efficacy Scale, and a series of questions related to the participants' ability to deal with stressful situations. Participants were asked to fill in this questionnaire to strengthen our cover story used to manipulate expectancy. Before coming to the lab and independently of their response to the questionnaire, participants were randomly assigned to the High Expectancy or Low Expectancy group.

Laboratory session: For the induction of stress response, participants attended an individual session. Participants were asked to sleep as usual and to abstain from alcohol and heavy physical exercise for 24 hours before the session. Additionally, they were instructed to drink only water, not eat, smoke, brush their teeth or take any stimulants (such as coffee, cola, caffeine, tea or chocolate) two hours before the session. Upon arrival to the laboratory, participants were interviewed to determine whether they had followed these instructions, and they were screened for past or current 
psychiatric diagnoses using the semi-structured Mini International Neuropsychiatric Interview (MINI screening version; Sheehan et al., 1998). After this short interview, the participants were asked to stay quiet in the room for $20 \mathrm{~min}$ to habituate to the laboratory. During the last $10 \mathrm{~min}$ of habituation, participants completed the baseline questionnaires (i.e., Perceived Stress Scale, Rosenberg SelfEsteem Scale, Ruminative Responses Scale, Beck Depression Inventory-II). After the habituation period, the participants received positive or negative feedback on their ability to deal with stressful situations (i.e., expectancy manipulation). They were informed that the questionnaire that they had to fill in online (at least two days before the session) was a questionnaire used to assess the ability of people to deal with socially stressful situations, such as giving a speech in front of a public, an oral examination, or a job interview. Participants in the High Expectancy group received the following feedback: "Your score is in the top 25\% of people with high control ability. This means that, comparing to other people, when you are in a stressful situation you are inclined to feel confident that you will be able to find a way to deal with it and you do not usually give up easily. As a result, your performance in this kind of situations (giving a speech in front of a public, an oral examination, a job interview, etc.) tends to be high." The participants in the Low Expectancy group received the opposite feedback: "Your score is in the top 25\% of people with low control ability. This means that comparing to other people, when you are in a stressful situation, you are inclined not to feel confident that you will be able to find a way to deal with it and you usually give up easily. As a result, your performance in this kind of situations (giving a speech in front of a public, an oral examination, a job interview, etc.) tends to be low." After receiving the feedback, participants were introduced to the stress task, and they were asked to prepare the task for $15 \mathrm{~min}$ (i.e., anticipatory phase). At the beginning of the anticipation phase, they completed the PASA ${ }^{3}$ to assess cognitive stress appraisal. After $15 \mathrm{~min}$ of anticipation, they performed the speech and the arithmetic task. After the stress task, the participants were asked to stay quiet for $40 \mathrm{~min}$ to recover from the task. At the end of the recovery phase,

\footnotetext{
${ }^{3}$ The participants also completed the Expectancy for stressful events questionnaire, a questionnaire developed in our laboratory to assess expectancy and acceptance in stressful situations. We do not include this scale in the analyses because the questionnaire is still in the process of validation.
} 
the participants' height and weight were measured to compute their body mass index. Finally, the participants were asked about the aim of the study, whether they thought that the feedback received during the session was real or a manipulation, and whether they participated in a similar stress task before. At the end of the session, participants were debriefed about the purpose of the study and were paid 15 euros for their participation.

During the laboratory session, participants provided six saliva samples to measure cortisol levels: (I) at the end of the habituation period, (II) ten minutes after the onset of the anticipation phase, (III) immediately after the speech task, (IV) 20 min after the onset of the stress task, (V) 35 min after the onset of the stress task, and (VI) $50 \mathrm{~min}$ after the onset of the stress task. To measure the psychological response to stress, participants were asked to fill in the VASs six times: (I) at the end of the habituation phase, (II) after the expectancy manipulation, (III) at the end of the anticipatory phase, (IV) after the speech task, (V) immediately after the arithmetic task, and (VI) 40 min after the end of the stress task. To measure HRV, the polar was adjusted at the beginning of the laboratory session and removed at the end of the recovery phase.

To control for the circadian rhythm of cortisol secretion, the experimental sessions started at $12.00 \mathrm{~h}, 16.00 \mathrm{~h}$ or $18.00 \mathrm{~h}$. The starting time was counterbalanced, and there were no significant differences between groups in the time when they started the session $\left(\chi^{2}=0.265, p=0.876, P h i=0.07\right)$.

\subsection{Data management and statistical analyses}

For HRV, the last $10 \mathrm{~min}$ of the habituation and anticipation phases, and the first 10 min of the recovery phase were separated into $5 \mathrm{~min}$ epochs and averaged to compute the HRV levels at baseline, anticipation, and recovery, respectively. HRV levels during the speech and the arithmetic tasks were averaged to compute the HRV levels during the stress task. As in our previous study, anticipatory HRV response was calculated as the change from baseline to anticipation in HRV levels (Pulopulos et al., 2018a). Lower values in anticipatory HRV response indicate worse anticipatory stress regulation. For cortisol levels, two indexes were computed and used as dependent variables for the analyses: (I) The area under the curve with respect to the increase (AUCi) was calculated, us- 
ing the six cortisol samples (see Pruessner et al., 2003 for the specific formula), as a measure of dynamic of the cortisol change during the session, (II) the cortisol reactivity was computed as the change in cortisol from baseline to the maximum cortisol levels after the stress task, as a measure of the magnitude of the cortisol response provoked by the stress task. Cortisol, HRV and VAS values did not show normal distributions, and they were log transformed.

$T$-tests were used to investigate differences between groups in demographics, baseline questionnaires, cognitive stress appraisal (i.e., Primary Appraisal, Secondary Appraisal and Tertiary Appraisal), and cortisol indexes (i.e., cortisol AUCi and cortisol reactivity). Mixed ANOVAs were used to investigate the psychological response to stress using Group (High Expectancy vs. Low Expectancy) as a between-subject factor and Time (Habituation, Manipulation, Anticipation, Stress, Recovery 1 and Recovery 2) as a within-subject factor. The nine VAS mood scales were the dependent variables. Mixed ANOVA was used to investigate differences between groups in the HRV response to stress using group (High Expectancy vs. Low Expectancy) as a between-subject factor and Time (Baseline, Anticipation, Stress, and Recovery) as a within-subject factor. When necessary, we applied the Greenhouse-Geisser correction to ensure the assumption of sphericity.

In mediation models, we investigated whether high expectancy leads to higher cortisol response to stress (cortisol reactivity and $A U C i$ ) via worse anticipatory stress regulation (anticipatory HRV response). Given that the anticipatory cognitive stress appraisal index reflects whether an individual perceives that she can deal with the stressful situation considering whether she perceives the situation as more threatful and/or challenging, this variable was used as the predictor in these models. As in our previous study, anticipatory HRV response was calculated as the change from baseline to anticipation in HRV levels (Pulopulos et al., 2018a). Lower values in anticipatory HRV response indicaterse anticipatory stress regulation. We used PROCESS 3.0 for SPSS (IBM SPSS Statistics 24.0) to test mediation effects, a tool that estimates the indirect effect of cognitive stress appraisal on cortisol indexes (cortisol reactivity and $A U C i$ ) via anticipatory HRV response (the change from baseline to anticipation in HRV levels), equivalent to the difference between the total effect (rela- 
tionship between cognitive stress appraisal and cortisol indexes not controlling for anticipatory HRV response) and the direct effect of the independent variable (relationship between cognitive stress appraisal and cortisol indexes controlling for anticipatory HRV response). To determine the significance of the indirect effect, PROCESS uses bootstrapped confidence intervals (Cls; significant when not overlapping zero; Hayes, 2017).

Sixty-seven women participated in this study. However, eight participants were excluded from the analyses due to the following reasons: Two participants were outliers $( \pm 3 S D)$ for the two cortisol indexes, one participant had missing data for baseline questionnaires and PASA, two participants had missing data for cortisol levels, and three participants indicated at the end of the session that they participated in a similar stress task in a previous experiment. We decided to exclude participants who performed a similar stress task in previous experiments because of the well-known habituation of the HPA axis response to the TSST (Schommer et al., 2003). Finally, seven participants indicated that they did not believe the feedback used to manipulate expectancy. The final sample included in the analyses was composed of 25 participants in the High Expectancy group, and 27 in the Low Expectancy group. Afterwards, the analyses were repeated including the participants who suspected that the feedback used to manipulate expectancy was part of the manipulation of the study (High Expectancy group=29, Low Expectancy group=30) (see supplementary material) ${ }^{4}$.

Analyses were performed using SPSS 24.0 (IBM SPSS Statistics 24.0), and the significance level was set at $p \leq 0.05$, two-tailed, for all analyses.

\section{Results}

\subsection{Demographics and baseline questionnaires}

Table 1 shows the characteristics of the study sample. No significant differences were observed between the High Expectancy and Low Expectancy groups in age, body mass index, subjective socioeconomic status (assessed using the subjective socioeconomic status scale: Adler et al., 2000),

\footnotetext{
${ }^{4}$ Overall, the statistical conclusions of the study remained the same if these participants are included in the analyses.
} 
and smoking, and their scores in depression symptoms, reflection, brooding, perceived stress in the past month, self-esteem, and general self-efficacy (all $p s>0.102$ ).

\subsection{Anticipatory cognitive appraisal}

Figure 1 shows the scores in cognitive stress appraisal for the High Expectancy and Low Expectancy groups. The Low Expectancy group showed higher primary appraisal $(t(50)=2.25, p=0.029$, $d=0.31)$ lower secondary appraisal $(t(50)=-2.04, p=0.047, d=0.28)$, and more negative anticipatory cognitive stress appraisal, $(t(50)=-2.46, p=0.017, d=0.34)$, indicating that the Low Expectancy group perceived the situation as more threatening and challenging, and they perceived that they have fewer resources to deal with the stressful situation than the High Expectancy group.

\subsection{Psychological response to stress}

Regarding the changes in mood during the session, the mixed ANOVA showed that the factor Time was statistically significant for tiredness, happiness, anxiety, tension, worry, anger, and stress $(p s<0.015)$. Follow-up analyses revealed that, compared to baseline levels, participants reported being more anxious and stressed during anticipation, after the speech and after the arithmetic task ( $p s<0.035)$, less happy and angrier after the speech and the arithmetic task $(p s<0.018)$, more worried during anticipation $(p=0.003)$, and more tense after expectancy manipulation, during anticipation, after the speech and after the arithmetic task $(p s<0.016)$. The factor Group was significant only for depression, showing that the Low Expectancy group reported more depressed feelings than the High Expectancy group $(p=0.025)$. Importantly, the interactions between Time and Group were not statistically significant for the nine VASs, indicating that the manipulation of expectation did not affect the stress-induced change in mood in our participants (ps>0.115) (see Table 2).

\subsection{Physiological response to stress}

Figure 2 shows HRV levels during the session for the High expectancy and Low Expectancy groups. The ANOVA for repeated measured showed a significant effect of Time $(F(2.03,99.42)=57.97$, 
$\left.p<0.001, \eta p^{2}=0.54\right)$. HRV showed a significant decrease from the habituation phase to the anticipation of the stress task ( $\left.p=0.024, d_{\mathrm{av}}=0.18\right)$. Also, HRV was lower during the stress task than during the anticipation phase $\left(p>0.001, d_{\mathrm{av}}=0.81\right)$. HRV during the recovery phase was higher than during habituation ( $\left.p<0.001, d_{\mathrm{av}}=0.29\right)$, anticipation $\left(p<0.001, d_{\mathrm{av}}=0.47\right)$, and the stress task $\left(p<0.001, d_{\mathrm{av}}=1.32\right)$. The factor Group (High Expectancy vs Low Expectancy) $\left(F(1,49)=0.54, p=0.468, \eta p^{2}=0.01\right.$ ), and the interaction between Time and Group were not statistically significant $(F(2.03,99.42)=0.79, p=0.460$, $\left.\eta p^{2}=0.02\right)$.

Figure $3 \mathrm{~A}$ shows the cortisol levels at each time point during the session for the High Expectancy and Low Expectancy groups. For the analyses with AUCi and cortisol reactivity, the Low Expectancy group showed higher values than the High Expectancy group (for AUCi, Low Expectancy: mean=-1.31, $S D=111.25$, High Expectancy: mean=-42.77, $S D=71.15$; for cortisol Reactivity, Low Expectancy: mean $=0.550, S D=0.49$, High Expectancy: mean $=-0.375, S D=0.29$ ), however, the differences were not statistically significant (AUCi: $t(44.39)=1.61, p=0.114, d=0.22$; cortisol Reactivity: $t(50)=1.48$, $p=0.141, d=0.21)$.

These results indicate that there were no differences between groups in anticipatory HRV response (i.e., the change from baseline to anticipation in HRV levels), HRV response to stress (i.e., changes in HRV from baseline to the stress task), and cortisol indexes (AUCi and cortisol reactivity). Importantly, in previous studies it has been demonstrated that depression symptoms, rumination, trait self-efficacy, self-esteem, and perceived stress may affect the HRV and cortisol response to stress (e.g., Chopra et al., 2009; Kemp et al., 2010; Key et al., 2008; O’Donnell et al., 2008; Pruessner et al., 2005; Puig-Perez et al., 2016; Salvador and Costa, 2009; Schönfeld et al., 2007; Schull et al., 2016; Vrshek-Schallhorn et al., 2018; Zoccola and Dickerson, 2012). Therefore, given that individual differences in these psychological factors may mask group differences in the HRV and cortisol response, we investigated whether anticipatory HRV response, HRV response to stress, AUCi and cortisol reactivity were significantly related to these baseline questionnaires. These analyses showed that general self-efficacy was significantly correlated with the anticipatory HRV response $(r=0.323$, 
$p=0.020)$, and that reflection was significantly associated with both AUCi $(r=-0.274, p=0.049)$ and cortisol reactivity $(r=-0.281, p=0.044)$. No significant relationships were observed between the anticipatory HRV response and brooding $(r=-0.052, p=0.716)$, reflection $(r=-0.047, p=0.739)$, perceived stress $(r=-0.217, p=0.122)$, self-esteem $(r=-0.032, p=0.822)$, and depression $(r=-0.236, p=0.092)^{5}$. None of the association with HRV response to stress were statistically significant $(p>0.282)$. Moreover, no significant relationships were observed between the cortisol indexes and brooding (AUCi: $r=-$ 0.122, $p=0.388$; cortisol Reactivity: $r=-0.163, p=0.248$ ), perceived stress (AUCi: $r=-0.181, p=0.200$; cortisol Reactivity: $r=-0.180, p=0.202$ ), self-esteem (AUCi: $r=-0.054, p=0.701$; cortisol Reactivity: $r=0.014, p=0.921$ ), depression (AUCi: $r=-0.136, p=0.337$; cortisol Reactivity: $r=-0.112, p=0.429$ ), and general self-efficacy (AUCi: $r=-0.206, p=0.142$; cortisol Reactivity: $r=-0.256, p=0.067)^{6}$.

Considering these results, we controlled for the effect general self-efficacy and reflection in the analyses investigating the difference in anticipatory HRV response and cortisol indexes, respectively. The ANCOVA with anticipatory HRV response as the dependent variable, Group (High Expectancy vs. Low Expectancy) as a between-subject factor and general self-efficacy a covariate showed a significant effect of general self-efficacy $\left(F(1,49)=5.92, p=0.019, \eta p^{2}=0.108\right)$. Although the Low expectancy group showed a larger decrease in HRV from baseline to anticipation (Low Expectancy: mean=-0.104, SEM=0.039, High Expectancy: mean=-0.58, SEM=0.041), the differences between groups were not statistically significant $\left(F(1,49)=0.66, p=0.419, \eta p^{2}=0.01\right)$. For the analyses with cortisol indexes, the results showed a significant effect of reflection on both $\operatorname{AUCi}(F(1,49)=6.46$, $\left.p=0.014, \eta p^{2}=0.12\right)$, and cortisol Reactivity $\left(F(1,49)=6.57, p=0.014, \eta p^{2}=0.12\right)$. Importantly, the Low Expectancy group show higher $A U C i\left(F(1,49)=4.87, p=0.032, \eta p^{2}=0.09\right.$; Figure $\left.3 B\right)$, and cortisol reactivity $\left(F(1,49)=4.42, p=0.041, \eta p^{2}=0.08\right.$; Figure $\left.3 C\right)$, than the High Expectancy group.

\footnotetext{
${ }^{5}$ Given that depression showed a marginally significant association with anticipatory HRV response, we also performed the ANCOVA for anticipatory HRV response including both general self-efficacy and depression as covariates. The result showed no significant effect of Group $\left(F(1,48)=4.03, p=0.470, \eta p^{2}=0.08\right)$. Importantly, general self-efficacy was a significant covariate in the analyses $\left(F(1,48)=4.79, p=0.033, \eta p^{2}=0.09\right)$, but depression was not $\left(F(1,48)=1.78, p=0.188, \eta p^{2}=0.03\right)$.

${ }^{6}$ Given that self-efficacy showed a marginally significant association with cortisol reactivity, we also performed the ANCOVA for cortisol Reactivity including both rumination reflection and general self-efficacy as covariates. The result showed higher cortisol reactivity in the Low Expectancy group than in the High Expectancy group $\left(F(1,48)=4.03, p=0.050, \eta p^{2}=0.08\right)$. Importantly, rumination reflection was a significant covariate in the analyses $\left(F(1,48)=5.29, p=0.026, \eta p^{2}=0.11\right)$, but general self-efficacy was not $\left(F(1,48)=2.23, p=0.142, \eta p^{2}=0.04\right)$.
} 


\subsection{Mediation analyses}

We hypothesized that anticipatory cognitive stress appraisal would explain the cortisol response to stress (i.e., Cortisol reactivity and $A U C i$ ) via anticipatory HRV response (i.e., the change in HRV levels from baseline to anticipation). We tested this hypothesis using mediation models. Given that lower baseline HRV was correlated to a lower decrease in HRV during anticipation ( $r=-0.293$, $p=0.035$ ), we included baseline HRV as covariates to control for the effect of individual differences in baseline (i.e., law of the initial values). Baseline cortisol levels were not significantly associated with cortisol reactivity $(r=-0.072, p=0.611)$ and $A U C i(r=-0.120, p=0.397)$, and therefore, this variable was not included as a covariate in the analyses. ${ }^{7}$

For cortisol reactivity, we observed that a more negative anticipatory cognitive stress appraisal was associated with larger decreases in HRV during stress anticipation (i.e., lower values in anticipatory HRV response) $(\beta=0.370, p=0.004)$. Moreover, individuals showing larger decreases in HRV during anticipation also showed higher cortisol reactivity $(\beta=-0.357, p=0.030)$. Importantly, the indirect effect (i.e., the effect of cognitive stress appraisal on cortisol reactivity via anticipatory HRV response) was statistically significant (Indirect effect $=-0.133, \mathrm{SE}=0.071,95 \% \mathrm{Cl}=0.285$ to 0.009 ). However, neither the total effect (i.e., effect of cognitive stress appraisal on cortisol reactivity without considering the anticipatory HRV response), nor the direct effect (i.e., effect of cognitive stress appraisal on cortisol reactivity controlling for the anticipatory HRV response) were significant (Total effect $=-0.090, \mathrm{SE}=0.143,95 \% \mathrm{Cl}=-0.377$ to 0.196 ; Direct effect $=0.042, \mathrm{SE}=0.150,95 \% \mathrm{Cl}=-0.259$ to $0.342)$.

For $A U C i$, we observed that individuals showing more negative cognitive stress appraisal showed larger decreases in HRV during stress anticipation (i.e., lower values in anticipatory HRV response) $(\beta=0.370, p=0.004)$. Moreover, individuals showing larger decreases in HRV during anticipa-

\footnotetext{
${ }^{7}$ Given that general self-efficacy and RRS reflection were related to anticipatory HRV response and cortisol indexes respectively, we repeated the analyses including these variables as covariates in the models. The statistical conclusions of the study are the same when general self-efficacy and RRS reflection are also included as covariates.
} 
tion also showed a higher $A U C i(\beta=-0.336, p=0.044)$. However, although the associations between cognitive stress appraisal, HRV and AUCi were significant, the indirect effect (i.e., the effect of cognitive stress appraisal on AUCi via anticipatory HRV response) was not statistically significant (Indirect effect $=-0.124, \mathrm{SE}=0.072,95 \% \mathrm{Cl}=-0.280$ to 0.006 ). The total effect (i.e., effect of cognitive stress appraisal on cortisol reactivity without taking into account the anticipatory HRV response), and the direct effect (i.e., effect of cognitive stress appraisal on cortisol reactivity controlling for the anticipatory HRV response) were not significant (Total effect $=-0.054, \mathrm{SE}=0.144,95 \% \mathrm{Cl}=-0.322$ to 0.235 ; Direct effect $=0.070, \mathrm{SE}=0.151,95 \% \mathrm{Cl}=-0.234$ to 0.375$)$.

As noted by Loeys and colleagues (2014), the power to detect an indirect effect may be higher than the power to detect a total effect. Therefore, the results for the total effects should be interpreted with caution.

\section{Discussion}

In this study, we investigated whether a manipulation of expectancy before a stressful situation affects the cortisol response to stress. We observed for the first time that individuals who received a negative feedback on their abilities to deal with social stressful situation (i.e., Low Expectancy group) anticipated the situation as more stressful and challenging, and perceived that they were less able to deal with the stressful task. Additionally, they showed a higher cortisol response to stress in comparison to the group that received a positive feedback (i.e., High Expectancy group) when the analyses are controlled for cognitive self-regulation. Moreover, we observed that more negative anticipatory cognitive stress appraisal was related to worse anticipatory stress regulation (i.e., indexed as more decrease in HRV during stress anticipation), and this led to higher cortisol response.

In accordance with our hypothesis, we observed that decreasing expectancy concerning future stressors, in comparison with increasing expectancy, leads to higher activation of the HPA axis in response to stress (i.e., cortisol reactivity and $A U C i$ ). This result is in line with previous studies showing that increasing expectations and anticipatory cognitive appraisal leads to better regulation of the stress-induced cortisol response (Gaab et al., 2003; Salzmann et al., 2018). Interestingly, optimism 
(defined in terms of generalized positive outcome expectancies) has been found to be predictive of less depressive symptoms in healthy individuals (e.g., Bromberger and Matthews, 1996; Cohen et al., 2001; Giltay et al., 2006; Shnek et al., 2001). Moreover, low expectancies regarding the ability to deal with future stressful events and negative evaluations of the future are observed in depressed patients, and people with anxiety disorders show low expectancy of being able to deal with futureoriented concerns (Beck, 1991; Beck and Clark, 1988; Haugen and Lund, 1999; Reiss, 1991). Following De Raedt and Koster (2010), it is possible that the exposition to higher levels of cortisol in stressful situations in healthy individuals with low expectancy provokes a reduction in DLPFC activity, and a prolonged activation of the amygdala, what in a long-term would reduce the ability to regulate emotions and contributes to the development of depression. Together, these results demonstrate that expectancy is a key factor to understanding the interindividual differences in the activation of the HPA-axis under stressful situations and explain to some extent how expectancy might be linked to the development of stress-related disorders.

The blunted cortisol response in the High Expectancy group is of interest to discuss. Although the stress task provoked a psychological and cardiovascular response in both groups, it moderately activated the HPA axis in the Low Expectancy, but not in the High Expectancy group. Given that one of the functions of the hormone cortisol is to mobilize resources to deal with stressful situations, one could also consider that a lack of cortisol increase, as it is observed in the High Expectancy group, might be a maladaptive response to stress. In line with this idea, previous research has also shown a relationship between blunted cortisol response to stress and risk factors for stress-related disorders (e.g., Avery and Vrshek-Schallhorn, 2016; Way et al., 2016; Zoola et al., 2008). However, two methodological characteristics of the current study should be considered. First, all the participants were taking hormonal contraceptives. Given that hormonal contraceptives reduce the cortisol response to stress (for reviews see Allen et al., 2014; Pulopulos et al., 2018b), it is possible that a more robust cortisol increase would be observed in both groups if a sample of women not taking hormonal contraceptives is investigated. Second, the stress severity of the version of the TSST used in this study 
was moderate-low. Importantly, in the cortisol reactivity threshold model, Vrshek-Schallhorn et al. (2018) have recently proposed that a relatively greater HPA axis activation to minor stressors is expected in individuals at high risk of developing depression, and a blunted or lower cortisol response would be expected in low-risk individuals. In contrast, the opposite pattern would be observed with major stressful events. In accordance with this model, we observed that a moderate-low severitylevel TSST triggered a higher activation of the HPA axis in the Low Expectancy than in the High Expectancy group. As proposed by Vrshek-Schallhorn et al. (2018), given that minor stressors are more common in daily life, individuals with less ability to deal with this kind of stressful events (e.g., persons with low expectancy) would experience more frequent HPA reactivity and higher exposure to high cortisol levels, what in long-run will lead to a dysregulation of the HPA-axis (McEwen, 2003) and a reduced ability to regulate emotions (De Raedt and Koster, 2010).

This study provides important evidence to understanding the regulatory mechanisms that occur during anticipation, and that may explain how expectancy may influence the cortisol response to stress. At a group level, a decrease in HRV from baseline to stress anticipation indicated that participants anticipated the stress task. Although no differences between groups in HRV response were observed, a mediation analysis revealed that worse anticipatory stress regulation (assessed as the change in HRV from baseline to the anticipatory phase) was observed in participants who anticipated the stress task as more threatening and challenging and who perceived that they have less ability to deal with the stressful situation. Moreover, worse anticipatory stress regulation was associated with a higher cortisol reactivity and (in the supplementary material) to higher AUCi. These results are in line with our recent study showing in a large sample of healthy individuals that less decrease in HRV during stress anticipation was associated with lower cortisol reactivity (Pulopulos et al., 2018a). Together, these findings can be interpreted according to the NFRE of De Raedt and Hooley (2016). This framework proposes that, when a stressful situation is anticipated, individuals with high expectancy will proactively anticipate the stressful situation leading to a sustained anticipatory activity of the dorsolateral prefrontal cortex (DLPFC), and inhibition of the amygdala. A decrease in the amygdala 
response to stress would result in a reduced HPA axis activation (Herman et al., 2005). Importantly, high HRV has been associated with successful emotion and stress regulation (Park et al., 2014; Thayer et al., 2012; Vanderhasselt et al., 2015), and with high prefrontal cortex activity (for meta-analyses see: Makovac et al., 2017; Thayer et al., 2012). Moreover, although we did not assess whether participants in the High Expectancy group used an adaptive stress regulation strategy, Nasso et al (2018) have recently demonstrated that individuals who proactively anticipate a stressful situation using cognitive reappraisal (i.e., an adaptive strategy of stress regulation) showed higher HRV during stress anticipation than individuals using catastrophizing (i.e., a non-adaptive regulatory strategy). Taken all together, these findings support the idea that individuals with high expectancy will successfully initiate mechanisms of anticipatory stress regulation (reflected in less decrease in HRV during stress anticipation), allowing them to prepare for the confrontation with the upcoming situation, and facilitating the confrontation with the stressful event, what in a long-run would be reflected in a lower cortisol response to stress.

For the whole sample, the stress task provoked changes in self-reported negative and positive affect; however, both groups showed a similar psychological stress response. These results are in accordance with most psychoendocrinological studies showing a lack of correspondence between physiological and affective responses to laboratory-based stress tasks (for a review see Campbell and Ehlert, 2012). As a possible explanation, it has been proposed that in comparison to the slow endocrine response, it is more difficult to detect the rapid changes in emotional states (Campbell and Ehlert, 2012; Schlotz et al., 2008). Even though no differences in mood changes were detected; the crucial result is that on the endocrinological level healthy females may become less sensitive to stressful events when they have positive expectancies.

The results of the current study are also of interest in placebo research. Previous studies have demonstrated that expectancy and anticipation play a central role in the placebo effect (Rief and Glombiewski, 2017), and it has been proposed that expectations about treatment success are the most prominent predictor of outcome in psychopharmacological and psychological interventions 
(Schedlowski et al., 2015). In our study, given that both groups did not differ in the trait measure of general self-efficacy and that the participants did not receive instructions or training to improve stress regulation, a placebo effect would be driving the enhanced stress regulation in the High Expectancy group. These observations suggest that the placebo mechanisms can be used to improve the effectiveness of interventions aimed at improving stress regulation.

Despite the novel findings, some limitations should be considered when interpreting the results of this study. To control for the effect of sex and menstrual cycle in the cortisol response to stress (Pulopulos et al., 2018b), only women taking hormonal contraceptives were included in the study. Although this may reduce the generalizability of our results, it is important to note that stressrelated disorders such as depression and anxiety are more common in women than in men (Bandelow and Michaelis, 2015; Kessler et al., 1994). Another limitation is that, although we assessed several psychological factors that may affect the stress response (i.e., perceived stress in the past month, self-efficacy, self-esteem, rumination and depression symptoms), we do not know whether the two groups have similar levels of social anxiety.

In conclusion, this study demonstrates the importance of expectancy and anticipatory stress regulation to understand the individual differences in the HPA axis response to stress. Our results suggest that people with negative expectancies concerning future stressful events may become more sensitive to stressful events (i.e., reflected in an exacerbated HPA axis response to stress), what in a long-term may contribute to the development of stress-related disorders. Our observations explain to some extent how positive expectancy may attenuate the cortisol response to stress through a successful initiation of mechanisms to regulate stress during anticipation, allowing the individuals to prepare themselves for the upcoming stressful event.

\section{Acknowledgment}

The authors would like to thank Nathan Van den Bergh and Jill van Put for their assistance with the translation of the PASA scale, Jens Allaert for his assistance with the Visual Analogue Scales, and Stefanie De Smet for her assistance with analyses of the HRV data. The work of MMP during this study has been supported by the Research Foundation Flanders (FWO18/PDO/174) and the Special Research Fund (BOF; 01P18916) at Ghent University. This work was also supported by Grant BOF16/GOA/017 for a Concerted Research Action of Ghent University (awarded to RDR \& CB). 


\section{References}

Adler, N.E., Epel, E.S., Castellazzo, G., Ickovics, J.R., 2000. Relationship of subjective and objective social status with psychological and physiological functioning: Preliminary data in healthy white women. Health Psychol. 19(6), 586-592. https://doi.org/10.1037/0278-6133.19.6.586

Allen, A.P., Kennedy, P.J., Cryan, J.F., Dinan, T.G., Clarke, G., 2014. Biological and psychological markers of stress in humans: Focus on the Trier Social Stress Test. Neurosci. Biobehav. Rev. 38, 94-124. https://doi.org/10.1016/j.neubiorev.2013.11.005

Avery, B.M., Vrshek-Schallhorn, S., 2016. Functional HTR2C polymorphism predicts cortisol response to psychosocial stress I: Effects in males and females. Psychoneuroendocrinology 70, 134-141.

Baeken, C., De Raedt, R., Van Schuerbeek, P., Vanderhasselt, M.A., De Mey, J., Bossuyt, A., Luypaert, R., 2010. Right prefrontal HF-rTMS attenuates right amygdala processing of negatively valenced emotional stimuli in healthy females. Behav. Brain Res. 214(2), 450-455.

https://doi.org/10.1016/j.bbr.2010.06.029

Baeken, C., Vanderhasselt, M.A., Remue, J., Rossi, V., Schiettecatte, J., Anckaert, E., De Raedt, R., 2014. One left dorsolateral prefrontal cortical HF-rTMS session attenuates HPA-system sensitivity to critical feedback in healthy females. Neuropsychologia. 57(1), 112-121. https://doi.org/10.1016/j.neuropsychologia.2014.02.019

Bandelow, B., Michaelis, S., 2015. Epidemiology of anxiety disorders in the 21st century. Dialog. Clin.I Neurosci. 17(3), 327-335. https://doi.org/10.1016/j.siny.2015.10.004

Beck, A.T., 1991. Cognitive Therapy and the Emotional Disorders. In Am. J. Psychother. (Vol. 31, p. 356). https://doi.org/10.1176/appi.psychotherapy.1977.31.4.633

Beck, A.T., Clark, D.A. 1988. Anxiety and depression: An information processing perspective. Anx. Res., 1(1), 23-36. https://doi.org/10.1080/10615808808248218 
Beck, A.T., Steer, R.A., Brown, G., 1996. Beck Depression Inventory-II. San Antonio. https://doi.org/10.1037/t00742-000

Bromberger, J.T., Matthews, K.A., 1996. A longitudinal study of the effects of pessimism, trait anxiety, and life stress on depressive symptoms in middle-aged woman. Psychol. Aging. 11, 207-213. https://doi.org/10.1037/0882-7974.11.2.207

Brosschot, J.F., Gerin, W., Thayer, J.F., 2006. The perseverative cognition hypothesis: A review of worry, prolonged stress-related physiological activation, and health. J. Psychosom. Res. 60(2), 113-124. https://doi.org/10.1016/j.jpsychores.2005.06.074

Brosschot, J.F., Verkuil, B., Thayer, J.F. 2017. Exposed to events that never happen: Generalized unsafety, the default stress response, and prolonged autonomic activity. Neurosci. Biobehav. Rev. 74, 287-296. https://doi.org/10.1016/j.neubiorev.2016.07.019

Campbell, J., Ehlert, U., 2012. Acute psychosocial stress: does the emotional stress response correspond with physiological responses?. Psychoneuroendocrinology 37(8), 1111-1134. https://doi.org/10.1016/j.psyneuen.2011.12.010

Chopra, K.K., Ravindran, A., Kennedy, S.H., Mackenzie, B., Matthews, S., Anisman, H., ... Levitan, R.D., 2009. Sex differences in hormonal responses to a social stressor in chronic major depression. Psychoneuroendocrinology 34(8), 1235-1241. https://doi.org/10.1016/j.psyneuen.2009.03.014

Cohen, L., De Moor, C., Amato, R.J., 2001. The association between treatment-specific optimism and depressive symptomatology in patients enrolled in a Phase I cancer clinical trial. Cancer 91(10), 1949-1955. https://doi.org/10.1002/1097-0142(20010515)91:10<1949::AIDCNCR1218>3.0.CO;2-A

Cohen, S., Kamarck, T., Mermelstein, R., 1983. A Global Measure of Perceived Stress. J. Health Soc. Behav. 24, 385-396. https://doi.org/10.2307/2136404 
De Raedt, R., Koster, E.H., 2010. Understanding vulnerability for depression from a cognitive Neurosci. perspective: A reappraisal of attentional factors and a new conceptual framework. Cogn. Aff. Behav. Neurosci. 10(1), 50-70. https://doi.org/10.3758/CABN.10.1.50

Dickerson, S.S., Gruenewald, T.L., Kemeny, M.E., 2004. When the social self is threatened: Shame, physiology, and health. J. Person. 72(6), 1191-1216. https://doi.org/10.1111/j.14676494.2004.00295.x

Duffing, T.M., Greiner, S.G., Mathias, C.W., \& Dougherty, D.M., 2014. Stress, substance abuse, and addiction. In Behavioral Neurobiology of Stress-related Disorders (pp. 237-263). Springer, Berlin, Heidelberg. https://doi.org/10.1007/7854_2014_276

Engert, V., Efanov, S.I., Duchesne, A., Vogel, S., Corbo, V., Pruessner, J.C., 2013. Differentiating anticipatory from reactive cortisol responses to psychosocial stress. Psychoneuroendocrinology 38(8), 1328-1337. https://doi.org/10.1016/j.psyneuen.2012.11.018

Fagundes, C.P., Murray, D.M., Hwang, B.S., Gouin, J.P., Thayer, J.F., Sollers, J.J., ... Kiecolt-Glaser, J.K., 2011. Sympathetic and parasympathetic activity in cancer-related fatigue: More evidence for a physiological substrate in cancer survivors. Psychoneuroendocrinology 36(8), 1137-1147. https://doi.org/10.1016/j.psyneuen.2011.02.005

Faravelli, C., Lo Sauro, C., Lelli, L., Pietrini, F., Lazzeretti, L., Godini, L., ... Ricca, V., 2012. The role of life events and HPA axis in anxiety disorders: a review. Curr. Pharm. Des. 18(35), 5663-5674. https://doi.org/CPD-EPUB-20120524-5 [pii]

Fekedulegn, D.B., Andrew, M.E., Burchfiel, C.M., Violanti, J.M., Hartley, T.A., Charles, L.E., Miller, D.B., 2007. Area under the curve and other summary indicators of repeated waking cortisol measurements. Psychosom. Med. 69(7), 651-659. https://doi.org/10.1097/PSY.0b013e31814c405c 
Franck, E., De Raedt, R., Barbez, C., Rosseel, Y., 2008. Psychometric properties of the Dutch Rosenberg self-esteem scale. Psychologica Belgica. 48(1), 25-35. https://doi.org/10.5334/pb-48-1-25

Gaab, J., Blättler, N., Menzi, T., Pabst, B., Stoyer, S., Ehlert, U., 2003. Randomized controlled evaluation of the effects of cognitive-behavioral stress management on cortisol responses to acute stress in healthy subjects. Psychoneuroendocrinology. 28(6), 767-779. https://doi.org/10.1016/S0306-4530(02)00069-0

Gaab, J., Rohleder, N., Nater, U.M., Ehlert, U., 2005. Psychological determinants of the cortisol stress response: The role of anticipatory cognitive appraisal. Psychoneuroendocrinology 30(6), 599610. https://doi.org/10.1016/j.psyneuen.2005.02.001

Giltay, E.J., Zitman, F.G., Kromhout, D., 2006. Dispositional optimism and the risk of depressive symptoms during 15 years of follow-up: The Zutphen Elderly Study. J. Aff. Dis. 91(1), 45-52. https://doi.org/10.1016/j.jad.2005.12.027

Haugen, R., Lund, T., 1999. The concept of general expectancy in various Person. dispositions. Scan. J. Psychol. 40(2), 109-114. https://doi.org/10.1111/1467-9450.00106

Hayes, A.F., 2017. Introduction to Mediation, Moderation, and Conditional Process Analysis: A Regression-based Approach. New York, NY: The Guliford Press. https://doi.org/10.5539/ass.v11n9p207

Herbert, J., 2013. Cortisol and depression: three questions for psychiatry. Psychol. Med. 43(3), 449469. https://doi.org/10.1017/S0033291712000955

Hergueta, T., Baker, R., \& Dunbar, G.C., (1998). The Mini-International Neuropsychiatric Interview (MINI): the development and validation of a structured diagnostic psychiatric interview for DSM-IVand ICD-10. J. Clin. Psychiatry. 59(Suppl 20), 2233. 
Herman, J.P., Ostrander, M.M., Mueller, N.K., Figueiredo, H., 2005. Limbic system mechanisms of stress regulation: hypothalamo-pituitary-adrenocortical axis. Prog. Neuropsychopharmacol. Biol. Psychiatry. 29(8), 1201-1213. https://doi.org/10.1016/j.pnpbp.2005.08.006

Juster, R.P., Perna, A., Marin, M.F., Sindi, S., Lupien, S.J., 2012. Timing is everything: Anticipatory stress dynamics among cortisol and blood pressure reactivity and recovery in healthy adults. Stress 15(6), 569-577. https://doi.org/10.3109/10253890.2012.661494

Kemp, A.H., Quintana, D.S., Gray, M.A., Felmingham, K.L., Brown, K., Gatt, J.M., 2010. Impact of depression and antidepressant treatment on heart rate variability: a review and meta-analysis. Biol Psychiat , 67 (11), 1067-1074. https://doi.org/10.1016/j.biopsych.2009.12.012

Key, B.L., Campbell, T.S., Bacon, S.L., Gerin, W., 2008. The influence of trait and state rumination on cardiovascular recovery from a negative emotional stressor. J. Behav. Med., 31 (3), 237-248. https://doi.org/10.1007/s10865-008-9152-9

Kessler, R.C., McGonagle, K.A., Nelson, C.B., Hughes, M., Swartz, M., Blazer, D.G., 1994. Sex and depression in the National Comorbidity Survey. II: Cohort effects. J. Aff. Dis. 30(1), 15-26. https://deepblue.lib.umich.edu/handle/2027.42/30529

Kirschbaum, C., Pirke, K.M., Hellhammer, D.H., 1993. The 'Trier Social Stress Test'-a tool for investigating psychobiological stress responses in a laboratory setting. Neuropsychobiology 28(1-2), 76-81. https://doi.org/10.1159/000119004

Laborde, S., Mosley, E., Thayer, J.F., 2017. Heart rate variability and cardiac vagal tone in psychophysiological research-recommendations for experiment planning, data analysis, and data reporting. Front. Psychol. 8, 213. https://doi.org/10.3389/fpsyg.2017.00213

Lazarus, R.S., 2001. Stress and Emotion: A New Synthesis. Risk Management 3(2), 69-70. https://doi.org/10.1057/palgrave.rm.8240089 
Lazarus, R.S., Folkman, S., 1987. Transactional theory and research on emotions and coping. Eur. J. Person. 1(3), 141-169. https://doi.org/10.1002/per.2410010304

Loeys, T., Moerkerke, B., Vansteelandt, S., 2015. A cautionary note on the power of the test for the indirect effect in mediation analysis. Front. Psychol. 5, 1549. https://doi.org/10.3389/fpsyg.2014.01549

Makovac, E., Thayer, J.F., Ottaviani, C., 2017. A meta-analysis of non-invasive brain stimulation and autonomic functioning: implications for brain-heart pathways to cardiovascular disease. Neurosci. Biobehav. Rev. 74, 330-341. https://doi.org/10.1016/j.neubiorev.2016.05.001

Manning, R.P., Dickson, J.M., Palmier-Claus, J., Cunliffe, A., Taylor, P.J., 2017. A systematic review of adult attachment and social anxiety. J. Aff. Dis. 211, 44-59. https://doi.org/10.1016/j.jad.2016.12.020

McCormack, H.M., Horne, D.J.D.L., Sheather, S., 1988. Clinical applications of visual analogue scales: a critical review. Psychol. Med. 18(4), 1007-1019. https://doi.org/10.1017/\$0033291700009934

McEwen, B.S., 2008. Central effects of stress hormones in health and disease: Understanding the protective and damaging effects of stress and stress mediators. Eur. J. Pharm. 583(2-3), 174185. https://doi.org/10.1016/j.ejphar.2007.11.071

Morris, M.C., Rao, U., Garber, J., 2012. Cortisol responses to psychosocial stress predict depression trajectories: Social-evaluative threat and prior depressive episodes as moderators. J. Aff. Dis. 143(1-3), 223-230. https://doi.org/10.1016/j.jad.2012.05.059

Nasso, S., Vanderhasselt, M., Demeyer, I., De Raedt, R., 2018. Autonomic Regulation in Response to Stress: The Influence of Anticipatory Emotion Regulation Strategies and Trait Rumination. Emotion https://doi.org/10.1037/emo0000448 
Nolen-Hoeksema, S., Morrow, J., 1991. A prospective study of depression and posttraumatic stress symptoms after a natural disaster: the 1989 Loma Prieta Earthquake. J. Person. Soc. Psychol. 61(1), 115-121. https://doi.org/10.1037/0022-3514.61.1.115

O'Donnell, K., Brydon, L., Wright, C.E., Steptoe, A., 2008. Self-esteem levels and cardiovascular and inflammatory responses to acute stress. Brain Behav. Immun., 22(8), 1241-1247. https://doi.org/10.1016/j.bbi.2008.06.012

Ottaviani, C., 2018. Brain-heart interaction in perseverative cognition. Psychophysiology e13082. https://doi.org/10.1111/psyp.13082

Park, G., Vasey, M.W., Van Bavel, J.J., Thayer, J.F., 2014. When tonic cardiac vagal tone predicts changes in phasic vagal tone: The role of fear and perceptual load. Psychophysiology 51(5), 419-426. https://doi.org/10.1111/psyp.12186

Pruessner, J.C., Baldwin, M.W., Dedovic, K., Renwick, R., Mahani, N.K., Lord, C., ... Lupien, S., 2005. Self-esteem, locus of control, hippocampal volume, and cortisol regulation in young and old adulthood. Neurolmage 28(4), 815-826. https://doi.org/10.1016/j.neuroimage.2005.06.014

Pruessner, J.C., Kirschbaum, C., Meinlschmid, G., Hellhammer, D.H., 2003. Two formulas for computation of the area under the curve represent measures of total hormone concentration versus time-dependent change. Psychoneuroendocrinology 28(7), 916-931. https://doi.org/10.1016/S0306-4530(02)00108-7

Puig-Perez, S., Villada, C., Pulopulos, M.M., Hidalgo, V., Salvador, A., 2016. How are neuroticism and depression related to the psychophysiological stress response to acute stress in healthy older people? Physiol. Behav. 156, 128-136. https://doi.org/10.1016/j.physbeh.2016.01.015

Pulopulos, M.M., Hidalgo, V., Puig-Pérez, S., Salvador, A., 2018. Psychophysiological response to social stressors: Relevance of sex and age. Psicothema 30(2), 171-176. 
https://doi.org/10.7334/psicothema2017.200

Pulopulos, M.M., Vanderhasselt, M.-A., De Raedt, R., 2018. Association between changes in heart rate variability during the anticipation of a stressful situation and the stress-induced cortisol response. Psychoneuroendocrinology 94, 63-71. https://doi.org/10.1016/j.psyneuen.2018.05.004

Raes, F., Hermans, D., Eelen, P., 2003. De Nederlandstalige versie van de Ruminative Response Scale en de Rumination on Sadness Scale (The Dutch version of the Rumination Response Scale and the Rumination on Sadness Scale). Gedragstherapie 36, 97-104.

Reiss, S., 1991. Expectancy model of fear, anxiety, and panic. Clin. Psychol. Rev. 11(2), 141-153. https://doi.org/10.1016/0272-7358(91)90092-9

Rief, W., Glombiewski, J.A., 2017. The role of expectations in mental disorders and their treatment Expectations. World Psychiatry. 16, 210-211. http://dx.doi.org/10.1002/ wps.20427World.

Rosenberg, M., 1965. Society and the Adolescent Self-Image. Princeton, NJ: Princeton University Press.

Salvador, A., Costa, R., 2009. Coping with competition: neuroendocrine responses and cognitive variables. Neurosci. Biobehav. Rev. 33(2), 160-170. https://doi.org/10.1016/j.neubiorev.2008.09.005

Salzmann, S., Euteneuer, F., Strahler, J., Laferton, J.A.C., Nater, U.M., Rief, W., 2018. Optimizing expectations and distraction leads to lower cortisol levels after acute stress. Psychoneuroendocrinology 88, 144-152. https://doi.org/10.1016/j.psyneuen.2017.12.011

Schedlowski, M., Enck, P., Rief, W., Bingel, U., 2015. Neuro-bio-behavioral mechanisms of placebo and nocebo responses: implications for clinical trials and clinical practice. Pharm. Rev. 67(3), 
697-730.

Schönfeld, P., Preusser, F., Margraf, J., 2017. Costs and benefits of self-efficacy: differences of the stress response and clinical implications. Neurosci. Biobehav. Rev., 75, 40-52. https://doi.org/10.1016/j.neubiorev.2017.01.031.

Schommer, N.C., Hellhammer, D.H., Kirschbaum, C., 2003. Dissociation between reactivity of the hypothalamus-pituitary-adrenal axis and the sympathetic-adrenal-medullary system to repeated psychosocial stress. Psychosom. Med. 65(3), 450-460.

Schulkin, J., 2011. Social allostasis: Anticipatory regulation of the internal milieu. Front. Evol. Neurosci. 2, 111. https://doi.org/10.3389/fnevo.2010.00111

Schulkin, J., McEwen, B.S., Gold, P.W., 1994. Allostasis, amygdala, and anticipatory angst. Neurosci. Biobehav. Rev. 18(3), 385-396. https://doi.org/10.1016/0149-7634(94)90051-5

Schwarzer, R., Jerusalem, M., 1995. Optimistic self-beliefs as a resource factor in coping with stress. In Extreme stress and communities: Impact and intervention. (pp. 159-177). Dordrecht: Springer Netherlands. https://doi.org/10.1007/978-94-015-8486-9_7

Sghir, H., Löffler, S., Ottenbacher, J., Stumpp, J., Hey, S., 2012. Investigation of different HRV parameters during an extended Trier Social Stress Test. In Proceedings of the 7th Conference of the European Study Group on Cardiovascular Oscillations.

Shnek, Z.M., Irvine, J., Stewart, D., Abbey, S., 2001. Psychological factors and depressive symptoms in ischemic heart disease. Health. Psychol. 20(2), 141. http://psycnet.apa.org/record/2001-16998007

Shull, A., Mayer, S.E., McGinnis, E., Geiss, E., Vargas, I., Lopez-Duran, N.L., 2016. Trait and state rumination interact to prolong cortisol activation to psychosocial stress in females. 
Psychoneuroendocrinology 74, 324-332. https://doi.org/10.1016/j.psyneuen.2016.09.004

Sinha, R., 2001. How does stress increase risk of drug abuse and relapse? Psychopharmacology 158(4), 343-359. https://doi.org/10.1007/s002130100917

Smeets, T., Cornelisse, S., Quaedflieg, C.W.E.M., Meyer, T., Jelicic, M., Merckelbach, H., 2012. Introducing the Maastricht Acute Stress Test (MAST): A quick and non-invasive approach to elicit robust autonomic and glucocorticoid stress responses. Psychoneuroendocrinology, 37, 1998-2008. http://dx.doi.org/10.1016/j.psyneuen.

2012.04.012.

Smyth, N., Thorn, L., Oskis, A., Hucklebridge, F., Evans, P., Clow, A., 2015. Anxious attachment style predicts an enhanced cortisol response to group psychosocial stress. Stress 18(2), 143-148. https://doi.org/10.3109/10253890.2015.1021676

Tarvainen, M.P., Niskanen, J.P., Lipponen, J.A., Ranta-Aho, P.O., Karjalainen, P.A., 2014. Kubios HRV heart rate variability analysis software. Comput. Methods Programs Biomed., 113 (1), 210-220.

Tarvainen, M.P., Ranta-Aho, P.O., Karjalainen, P.A., 2002. An advanced detrending method with application to HRV analysis. IEEE Trans. Biomed. Eng., 49(2), 172-175.

Teeuw, B., Schwarzer, R., Jerusalem, M., 1994. Dutch Adaptation of the General Self-Efficacy Scale. Berlin. Retrieved August 12, 2018, from http://userpage.fu-berlin.de/ health/dutch.htm

Thayer, J.F., Åhs, F., Fredrikson, M., Sollers III, J.J., Wager, T.D., 2012. A meta-analysis of heart rate variability and neuroimaging studies: implications for heart rate variability as a marker of stress and health. Neurosci. Biobehav. Rev. 36(2), 747-756.

https://doi.org/10.1016/j.neubiorev.2011.11.009

Turan, B., Foltz, C., Cavanagh, J.F., Alan Wallace, B., Cullen, M., Rosenberg, E.L., ... Kemeny, M.E., 
2015. Anticipatory sensitization to repeated stressors: The role of initial cortisol reactivity and meditation/emotion skills training. Psychoneuroendocrinology 52(1), 229-238. https://doi.org/10.1016/j.psyneuen.2014.11.014

Ursin, H., Eriksen, H.R., 2010. Cognitive activation theory of stress (CATS). Neurosci. Biobehav. Rev. 34(6), 877-881. https://doi.org/10.1016/j.neubiorev.2009.03.001

Van der Does, A.J.W. 2002. Manual of the Dutch version of the BDI-II. San Antonio, TX/Lisse, Ed.

Vanderhasselt, M.A., Remue, J., Ng, K.K., Mueller, S.C., De Raedt, R., 2015. The regulation of positive and negative social feedback: A psychophysiological study. Cogn. Aff. Behav. Neurosci. 15(3), 553-563. https://doi.org/10.3758/s13415-015-0345-8

Vrshek-Schallhorn, S., Avery, B.M., Ditcheva, M., Sapuram, V.R., 2018. The cortisol reactivity threshold model: Direction of trait rumination and cortisol reactivity association varies with stressor severity. Psychoneuroendocrinology 92, 113-122. https://doi.org/10.1016/j.psyneuen.2017.11.002

Way, B.M., Brown, K.W., Quaglia, J., McCain, N., Taylor, S.E., 2016. Nonsynonymous HTR2C polymorphism predicts cortisol response to psychosocial stress II: Evidence from two samples. Psychoneuroendocrinology 70, 142-151.

Zandara, M., Garcia-Lluch, M., Pulopulos, M.M., Hidalgo, V., Villada, C., Salvador, A., 2016. Acute stress and working memory: The role of sex and cognitive stress appraisal. Physiol. Behav. 164, 336-344. https://doi.org/10.1016/j.physbeh.2016.06.022

Zoccola, P.M., Dickerson, S.S., 2012. Assessing the relationship between rumination and cortisol: A review. J. Psychosom. Res. 73(1), 1-9. https://doi.org/10.1016/j.jpsychores.2012.03.007

Zoccola, P.M., Dickerson, S.S., Zaldivar, F.P., 2008. Rumination and cortisol responses to laboratory stressors. Psychosom. Med. 70, 661-667. 


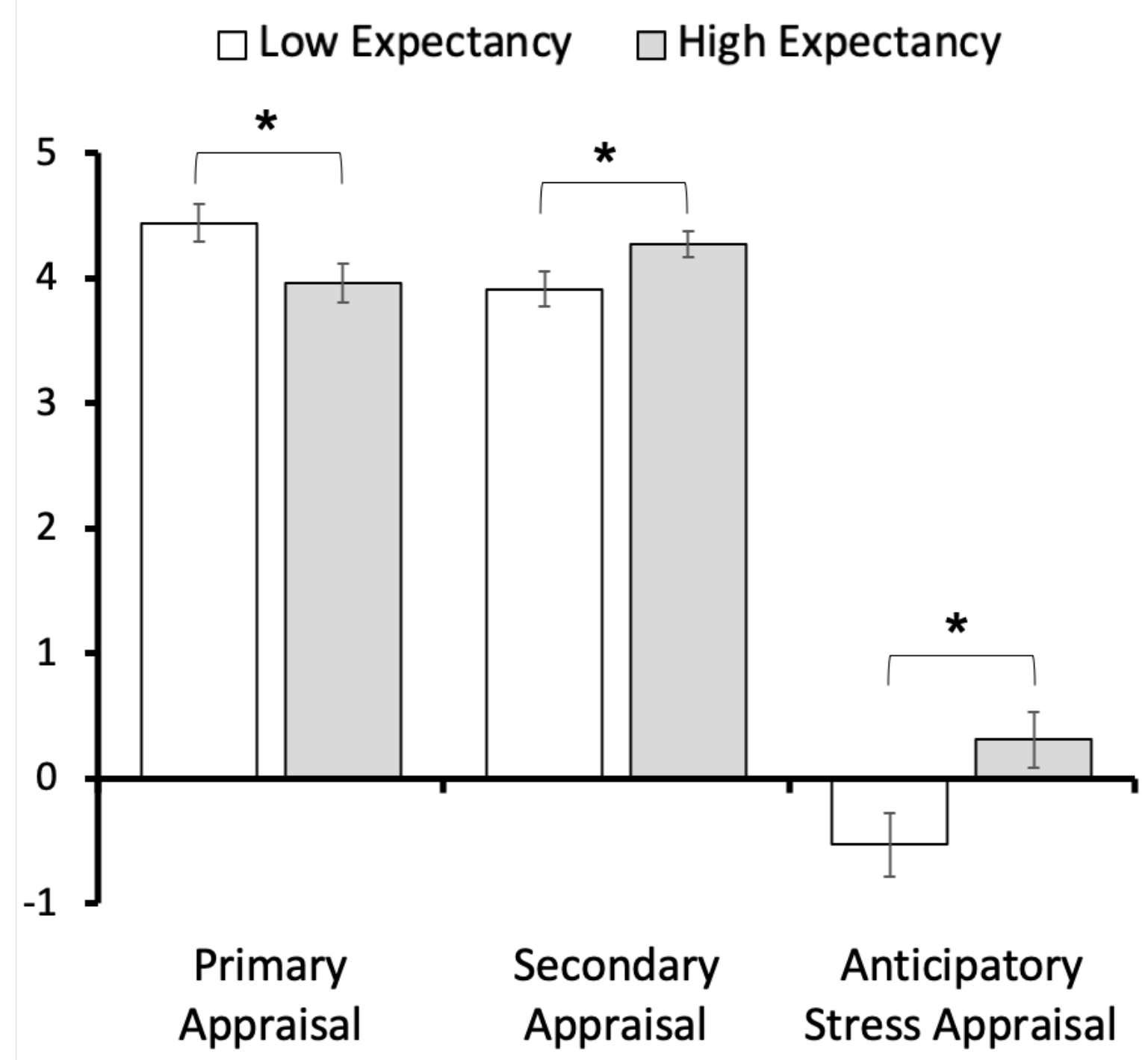

Figure 1. Primary appraisal, secondary appraisal and global anticipatory cognitive stress appraisal scores for the Low Expectancy (white) and the High Expectancy (grey) groups. Means and standard errors. ${ }^{*} p<0.05$ 


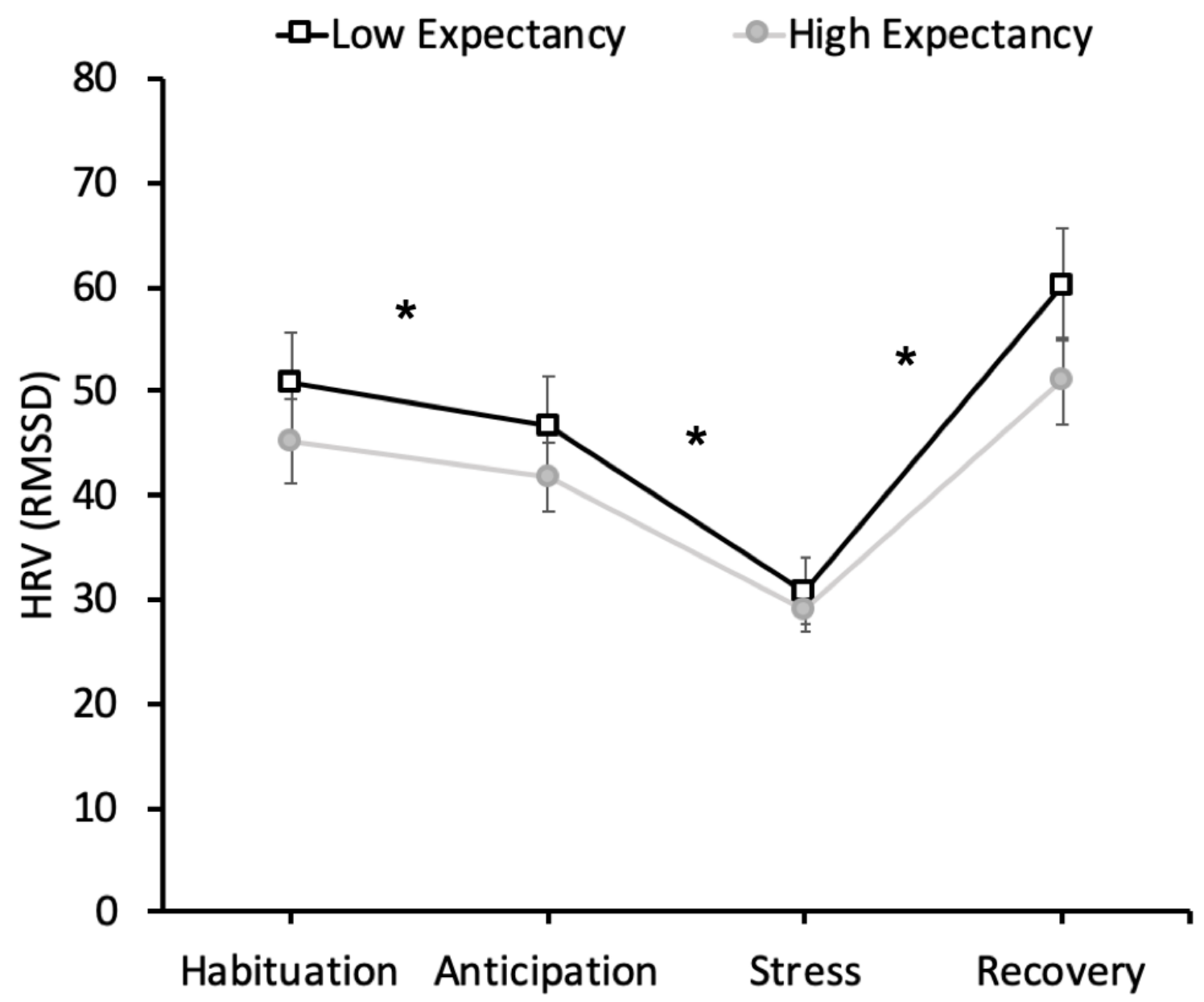

Fig 2. Heart rate variability (RMSSD) during the habituation, stress anticipation, stress task, and recovery. Means and standard errors. ${ }^{*} p<0.05$ 


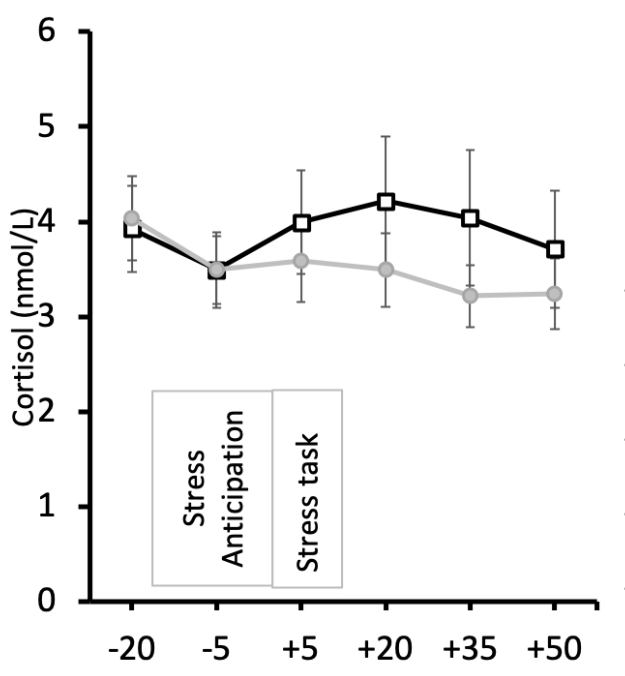

-Low Expectancy -o-High Expectancy
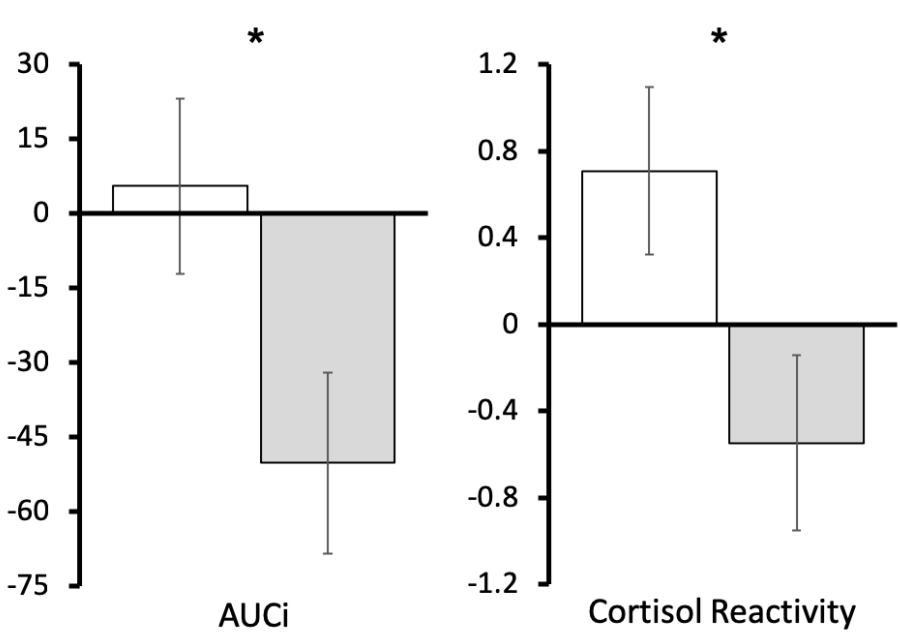

$\square$ Low Expectancy $\quad \square$ High Expectancy

Fig 3. (FigA) Cortisol (nmol/L) levels during the session. (Fig3B) AUCi levels for the Low Expectancy (white) and the High Expectancy (grey) group controlled for reflection scores. (Fig3C) Cortisol reactivity levels for the Low Expectancy (white) and the High Expectancy (grey) group controlled for reflection scores. Means and standard errors. ${ }^{*} p<0.05$ 
Table 1. Characteristics of the sample.

\begin{tabular}{|c|c|c|c|c|c|c|}
\hline & Group & Mean/n & SEM & $t / x^{2}$ & $p$ & Effect size \\
\hline \multirow[t]{2}{*}{ Age } & $\mathrm{L}$ & 20.52 & 0.40 & -0.766 & 0.448 & $d=0.10$ \\
\hline & $\mathrm{H}$ & 21.00 & 0.49 & & & \\
\hline \multirow[t]{2}{*}{ BMI } & $\mathrm{L}$ & 22.43 & 0.65 & 0.178 & 0.860 & $d=0.02$ \\
\hline & $\mathrm{H}$ & 22.28 & 0.58 & & & \\
\hline \multirow[t]{2}{*}{ Smoke } & $\mathrm{L}$ & $\mathrm{No}=27, \mathrm{Yes}=0$ & & 2.246 & 0.134 & Phi $=0.21$ \\
\hline & $\mathrm{H}$ & $\mathrm{No}=23, \mathrm{Yes}=2$ & & & & \\
\hline \multirow[t]{2}{*}{ SES } & $\mathrm{L}$ & 6.11 & 0.28 & 0.084 & 0.933 & $d=0.01$ \\
\hline & $\mathrm{H}$ & 6.08 & 0.24 & & & \\
\hline \multirow[t]{2}{*}{ PSS } & $\mathrm{L}$ & 22.70 & 1.36 & -0.371 & 0.713 & $d=0.05$ \\
\hline & $\mathrm{H}$ & 23.40 & 1.29 & & & \\
\hline \multirow[t]{2}{*}{ RRS Reflection } & $\mathrm{L}$ & 9.37 & 0.69 & 1.667 & 0.102 & $d=0.23$ \\
\hline & $\mathrm{H}$ & 7.80 & 0.64 & & & \\
\hline \multirow[t]{2}{*}{ RRS Brooding } & $\mathrm{L}$ & 9.30 & 0.58 & 0.533 & 0.597 & $d=0.08$ \\
\hline & $\mathrm{H}$ & 8.88 & 0.51 & & & \\
\hline \multirow[t]{2}{*}{ RSEQ } & L & 22.00 & 0.94 & 0.706 & 0.483 & $d=0.10$ \\
\hline & $\mathrm{H}$ & 21.08 & 0.89 & & & \\
\hline \multirow[t]{2}{*}{ BDI } & $\mathrm{L}$ & 6.22 & 1.15 & 0.788 & 0.434 & $d=0.11$ \\
\hline & $\mathrm{H}$ & 4.92 & 1.18 & & & \\
\hline \multirow[t]{2}{*}{ GSE } & L & 29.63 & 0.73 & 0.275 & 0.785 & $d=0.04$ \\
\hline & $\mathrm{H}$ & 29.40 & 0.41 & & & \\
\hline
\end{tabular}

Note: L=Low expectancy group; $\mathrm{H}=$ High expectancy group; BMI=Body Mass Index; SES=Subjective socioeconomic status; PSS=Perceived Stress Scale; RRS=Ruminative Response Scale; RSEQ= Rosenberg SelfEsteem Questionnaire; BDI= Beck Depression Inventory; GSE= General Self-Efficacy Scale 
Table 2. Mean (SD) and results of the repeated measure ANOVA for the VAS values.

\begin{tabular}{|c|c|c|c|c|c|c|c|c|}
\hline & & Habituat. & Manipulat. & Anticip. & Stress & Recov. 1 & Recov. 2 & \\
\hline \multirow[t]{2}{*}{ Tired } & $\mathbf{L}$ & $3.24(1.1)$ & $2.86(1.3)$ & $2.87(1.2)$ & $2.83(1.3)$ & $2.73(1.3)$ & $3.07(1.3)$ & Time: $F(2.74,112.40)=3.78, p=0.015, \eta p^{2}=0.08$ \\
\hline & H & $3.16(1.2)$ & $3.02(1.2)$ & $3.06(1.1)$ & $2.84(1.3)$ & $2.85(1.2)$ & $3.55(0.9)$ & $\begin{array}{l}\text { Group: } F(1,41)=0.23, p=0.634, \eta p^{2}=0.01 \\
\text { Time*Group: } F(2.74,112.40)=0.81, p=0.483, \eta p^{2}=0.02\end{array}$ \\
\hline \multirow[t]{3}{*}{ Happy } & $\mathbf{L}$ & $4.14(0.2)$ & $4.06(0.3)$ & $3.94(0.4)$ & $3.76(0.7)$ & $3.72(0.6)$ & $4.08(0.3)$ & Time: $F(2.64,108.20)=7.02, p<0.001, \eta p^{2}=0.15$ \\
\hline & H & $4.22(0.3)$ & $4.25(0.2)$ & $4.13(0.2)$ & $4.03(0.4)$ & $3.99(0.6)$ & $3.97(0.6)$ & Group: $F(1,41)=2.36, p=0.132, \eta p^{2}=0.05$ \\
\hline & & & & & & & & Time*Group: $F(2.64,108.20)=2.08, p=0.115, \eta p^{2}=0.05$ \\
\hline \multirow[t]{3}{*}{ Motivated } & $\mathbf{L}$ & $4.07(0.3)$ & $3.92(0.8)$ & $4.04(0.4)$ & $3.83(0.8)$ & $3.63(1.1)$ & $3.77(1.0)$ & Time: $F(2.53,103.60)=4.34, p=0.010, \eta p^{2}=0.10$ \\
\hline & H & $4.05(0.4)$ & $4.18(0.2)$ & $4.11(0.3)$ & $4.02(0.4)$ & $3.93(0.6)$ & $3.55(1.1)$ & Group: $F(1,41)=0.46, p=0.500, \eta p^{2}=0.01$ \\
\hline & & & & & & & & Time*Group: $F(2.53,103.60)=1.45, p=0.238, \eta p^{2}=0.03$ \\
\hline \multirow[t]{3}{*}{ Anxious } & $\mathbf{L}$ & $1.94(1.4)$ & $2.20(1.1)$ & $3.43(0.9)$ & $2.78(1.4)$ & $2.69(1.5)$ & $1.79(1.4)$ & Time: $F(3.85,157.67)=22.75, p<0.001, \eta p^{2}=0.36$ \\
\hline & $\mathbf{H}$ & $1.91(1.1)$ & $1.88(1.3)$ & $3.12(1.1)$ & $2.75(1.2)$ & $2.26(1.1)$ & $1.50(1.0)$ & Group: $F(1,41)=0.666, p=0.419, \eta p^{2}=0.02$ \\
\hline & & & & & & & & Time*Group: $F(3.85,157.67)=0.43, p=0.778, \eta p^{2}=0.01$ \\
\hline \multirow[t]{3}{*}{ Depressive } & $\mathbf{L}$ & $2.05(1.3)$ & $1.97(1.2)$ & $2.02(1.1)$ & $2.12(1.2)$ & $2.17(1.3)$ & $1.82(1.4)$ & Time: $F(3.30,135.35)=1.34, p=0.262, \eta p^{2}=0.03$ \\
\hline & H & $1.65(1.0)$ & $1.42(0.9)$ & $1.46(0.9)$ & $1.34(0.9)$ & $1.36(0.8)$ & $1.18(0.8)$ & Group: $F(1,41)=5.39, p=0.025, \eta p^{2}=0.12$ \\
\hline & & & & & & & & Time*Group: $F(3.30,135.35)=0.64, p=0.640, \eta p^{2}=0.01$ \\
\hline \multirow[t]{3}{*}{ Tense } & $\mathbf{L}$ & $2.62(1.3)$ & $3.47(0.8)$ & $3.97(0.5)$ & $3.75(1.0)$ & $3.63(1.0)$ & $2.37(1.3)$ & Time: $F(3.87,158.63)=29.74, p<0.001, \eta p^{2}=0.42$ \\
\hline & H & $2.85(1.2)$ & $3.07(0.9)$ & $3.74(0.7)$ & $3.66(0.5)$ & $3.59(0.7)$ & $2.31(1.2)$ & Group: $F(1,41)=0.23, p=0.635, \eta p^{2}=0.01$ \\
\hline & & & & & & & & Time*Group: $F(3.87,158.63)=0.92, p=0.451, \eta p^{2}=0.02$ \\
\hline \multirow[t]{3}{*}{ Worried } & $\mathbf{L}$ & $3.10(1.1)$ & $3.25(0.8)$ & $3.80(0.6)$ & $3.20(1.4)$ & $3.40(0.9)$ & $2.45(1.3)$ & Time: $F(3.73,152.93)=10.70, p<0.001, \eta p^{2}=0.21$ \\
\hline & H & $2.65(1.2)$ & $2.47(1.2)$ & $3.36(1.1)$ & $3.13(1.0)$ & $2.81(1.2)$ & $2.20(1.3)$ & Group: $F(1,41)=2.93, p=0.093, \eta p^{2}=0.07$ \\
\hline & & & & & & & & Time*Group: $F(3.73,152.93)=0.96, p=0.418, \eta p^{2}=0.02$ \\
\hline \multirow[t]{3}{*}{ Angry } & $\mathbf{L}$ & $1.67(1.0)$ & $1.44(1.0)$ & $1.87(1.2)$ & $2.39(1.3)$ & $2.52(1.4)$ & $1.82(1.1)$ & Time: $F(3.53,137.46)=10.35, p<0.001, \eta p^{2}=0.20$ \\
\hline & H & $1.37(1.0)$ & $1.54(0.9)$ & $1.63(1.0)$ & $2.18(1.2)$ & $2.38(1.2)$ & $1.52(1.1)$ & Group: $F(1,41)=0.52, p=0.474, \eta p^{2}=0.03$ \\
\hline & & & & & & & & Time*Group: $F(3.53,137.46)=0.36, p=0.807, \eta p^{2}=0.01$ \\
\hline \multirow[t]{3}{*}{ Stressed } & $\mathbf{L}$ & $2.83(1.2)$ & $3.31(1.0)$ & $3.81(0.7)$ & $3.90(0.6)$ & $3.49(1.0)$ & $2.20(1.3)$ & Time: $F(3.51,143,99)=32.41, p<0.001, \eta p^{2}=0.44$ \\
\hline & H & $2.52(1.3)$ & $2.80(1.1)$ & $3.64(1.0)$ & $3.74(0.6)$ & $3.41(0.7)$ & $2.05(1.2)$ & Group: $F(1,41)=1.04, p=0.314, \eta p^{2}=0.03$ \\
\hline & & & & & & & & Time*Group: $F(3.51,143,99)=0.47, p=0.734, \eta p^{2}=0.01$ \\
\hline
\end{tabular}

Note: L=Low expectancy group; $\mathrm{H}=$ High expectancy group 


\title{
Supplementary material
}

\section{Cortisol response to stress: The role of expectancy and an- ticipatory stress regulation.}

\author{
Matias M. Pulopulos, Chris Baeken and Rudi De Raedt
}

We repeated the analyses including the participants who suspected that the feedback on their ability to deal with stressful situations was part of the manipulation of the experiment. The sample included in the analyses consists of 29 participants in the High expectancy group and 30 participants in the Low expectancy group.

\section{Results}

Demographics, and baseline questionnaires

No significant differences were observed between the High expectancy and Low expectancy groups in age $(p=0.428)$, body mass index $(p=0.743)$, subjective socioeconomic status $(p=0.929)$, smoking $(p=0.143)$, depression symptoms $(p=0.633)$, brooding $(p=0.388)$, perceived stress in the past month $(p=0.498)$, and general self-efficacy $(p=0.440)$. Participants in the Low expectancy group reported slightly higher levels of reflection $(p=0.055)$ and self-esteem $(p=0.077)$.

\section{Anticipatory cognitive appraisal}

The Low expectancy group showed slightly higher primary appraisal $(p=0.084)$ and lower secondary appraisal $(p=0.095)$, and more negative anticipatory cognitive stress appraisal $(p=0.050)$. The result of anticipatory cognitive stress appraisal indicates that the Low expectancy group perceived the situation as more threatening and challenging, and that they perceived that they have fewer resources to deal with the stressful situation than the High expectancy group.

\section{Psychological response to stress}


Due to missing data, only 24 participants in the High expectancy group and 27 participants in the Low expectancy group were included in the analyses. Regarding the changes in mood during the session, the mixed ANOVAs with Group (High expectancy vs Low expectancy) as between-subject factor, Time (Habituation, Manipulation, Anticipation, Stress, Recovery 1 and Recovery 2) as withinsubject factor, and the nine VAS mood scales as the dependent variables showed that the factor Time was statistically significant for tiredness, happiness, motivation, anxiety, tension, worriedness, anger, and stress $(F(5,245)>4.17, p s<0.008)$. Follow-up analyses revealed that, compared to baseline levels, participants reported being less happy and more anxious during anticipation, after the speech and after the arithmetic task $(p s<0.012)$, angrier after the speech and the arithmetic task $(p s<0.011)$, more worried during anticipation $(p=0.001)$, more tense and stressed after expectancy manipulation, during anticipation, after the speech and after the arithmetic task ( $p s<0.037)$, and less motivated at the end of the session $(p=025)$. The factor Group was statistically significant only for depression, showing that the Low expectancy group reported more depressed feelings than the High expectancy group $(F(1,49)=5.45, p=0.024)$. Importantly, the interaction between Time and Group were not statistically significant for the nine VASs, indicating that the manipulation of expectation did not affect the stress-induced change in mood in our participants $(F(5,245)<1.82, p s>0.150)$.

\section{Physiological response to stress}

The mixed ANOVA with group (High expectancy vs Low expectancy) as between-subject factor and Time (Baseline, Anticipation, Stress, and Recovery) as a within-subject factor showed a significant effect of Time $(F(2.08,116.54)=69.80, p<0.001)$, HRV decreased significantly from the habituation phase to the anticipation of the stress task $(p=0.009)$. Also, HRV was lower during the stress task than during both the habituation and the anticipation phase $(p<0.001)$. HRV during the recovery phase was higher than during baseline, anticipation, and the stress task $(p s<0.002)$. The factor Group (High expectancy vs Low expectancy) $(F(1,56)=2.31, p=0.633)$, and the interaction between Time and Group $(F(2.08,116.54)=0.42, p=0.665)$ were not statistically significant. The ANCOVA with anticipa- 
tory HRV response as the dependent variable, Group (High Expectancy vs. Low Expectancy) as a between-subject factor and general self-efficacy a covariate showed a significant effect of general self-efficacy $\left(F(1,56)=9.73, p=0.003, \eta p^{2}=0.148\right)$. Although the Low expectancy group showed a larger decrease in HRV from baseline to anticipation (Low Expectancy: mean=-0.94, SEM=0.038, High Expectancy: mean $=-0.85, \mathrm{SEM}=0.038$ ), the differences between groups were not statistically significant $\left(F(1,56)=0.32, p=0.858, \eta p^{2}=0.01\right)$.

The ANCOVA with cortisol indexes as the dependent variable, Group (High expectancy vs. Low expectancy) as between-subject factor and reflection as a covariate showed a significant effect of reflection (AUCi: $F(1,56)=4.83, p=0.032$; Cortisol reactivity: $F(1,56)=5.44, p=0.023$ ) and a significant effect of the factor Group (AUCi: $F(1,56)=4.81, p=0.032$; Cortisol reactivity: $F(1,56)=4.83, p=0.032$ ). The Low expectancy group show higher AUCi (mean=7.19, SE=16.14), and cortisol reactivity (mean=0.72, SE=0.36), than the High expectancy group (AUCi: mean=-45.41, SE=16.43; Cortisol reactivity: mean=-0.47, $\mathrm{SE}=0.36$ ).

\section{Mediation analyses}

Using mediation models, we investigated whether high expectancy leads to higher cortisol response to stress (cortisol reactivity and $A U C i$ ) via worse anticipatory stress regulation (anticipatory HRV response). As observed for the analyses reported in the manuscript, lower baseline HRV was correlated to a lower decrease in HRV during anticipation $(r=-0.323, p=0.013)$. Therefore, we included baseline HRV as covariates to control for the effect of individual differences in baseline (i.e., law of the initial values). Baseline cortisol levels were not significantly associated with cortisol reactivity ( $r=-$ 0.106, $p=0.425)$ and $A U C i(r=-0.153, p=0.247)$, and therefore, this variable was not included as a covariate in the analyses.

We observed that a more negative anticipatory cognitive stress appraisal was associated with larger decreases in HRV during stress anticipation (i.e., lower values in anticipatory HRV response) 
$(\beta=0.387, p=0.020)$. Moreover, individuals showing larger decreases in HRV during anticipation also showed higher cortisol reactivity $(\beta=-0.372, p=0.012)$ and AUCi $(\beta=-0.351, p=0.020)$. Importantly, the indirect effect (i.e., the effect of cognitive stress appraisal on cortisol reactivity and AUCi via anticipatory HRV response) for cortisol reactivity and AUCi were both statistically significant (Cortisol reactivity: Indirect effect=-0.144, SE=0.068, 95\% Cl=-0.294 to -0.027 ; AUCi: Indirect effect=-0.136, SE=0.067, $95 \% \mathrm{Cl}=-0.281$ to -0.017$)$. However, the total effect (Cortisol reactivity: total effect $=-0.124, \mathrm{SE}=0.134$, $95 \% \mathrm{Cl}=-0.393$ to 0.145 ; $\mathrm{AUCi}$ : total effect=-0.086, $\mathrm{SE}=0.136,95 \% \mathrm{Cl}=-0.358$ to 0.187 ), and the direct effect (Cortisol reactivity: Direct effect=0.020, $\mathrm{SE}=0.139,95 \% \mathrm{Cl}=-0.259$ to 0.299; AUCi: Direct effect $=0.050, \mathrm{SE}=0.142,95 \% \mathrm{Cl}=-0.253$ to 0.335 ) were not significant. 